\title{
Создание новых форм редиса и редьки (Raphanus sativus L.) с прогнозируемым комплексом хозяйственно ценных признаков при использовании методологии ускоренной селекции
}

\section{А.А. Кочетов, Н.Г. Синявина}

В Агрофизическом научно-исследовательском институте (ФГБНУ АФИ) при использовании оригинальной методологии ускоренной селекции получены новые высокопродуктивные формы Raphanus sativus L., предназначенные для выращивания в открытом грунте Ленинградской области (дайкон) и в условиях интенсивной светокультуры (линии редиса и гибриды $\mathrm{F}_{1}$ редиса и дайкона). Цель исследований - усовершенствование разработанной авторами методологии ускоренной селекции при создании новых высокопродуктивных форм Raphanus sativus L., адаптированных к конкретным условиям выращивания. При проведении исследований изучено внутривидовое разнообразие корнеплодных культур вида Raphanus sativus L. (более 60 образцов разных эколого-географических групп и происхождения) при выращивании их в интенсивной светокультуре. Растения культивировали под лампами ДНаТ-400 и ДНаЗ-400 при облучении 70-80 Вт/м² ФАР. Корнеобитаемой средой служил торф с минеральными добавками, увлажняемый ежедневно раствором 1 н Кнопа при чередовании с водой. Оценена реакция различных сортов лобы и дайкона (35 образцов) на действие длинного дня (18-часовой фотопериод) и низких яровизирующих температур, провоцирующих преждевременное цветение. Выделены наиболее резистентные к этим факторам образцы, при гибридизации которых получены трансгрессивные формы дайкона с комплексной устойчивостью к раннему стеблеванию. На их основе создан высокопродуктивный сорт дайкона Петербургский, обладающий устойчивостью к действию длинного дня и пониженных температур, предназначенный для весенних посадок в открытый грунт Ленинградской области. При селекции редиса разработана и реализована стратегия получения высокопродуктивных форм, адаптированных для выращивания в интенсивной светокультуре. Выявлены сорта, способные обеспечивать урожай корнеплодов товарного качества до 3 кг/м² за 25 суток вегетации, а также сорта редиса - источники хозяйственно ценных признаков, реализуемых в этих условиях (максимальная длина/диаметр корнеплода, короткий вегетационный период, устойчивость к стеблеванию, компактная розетка листьев, неопушенный лист и др. Подобраны комбинации скрещивания, в потомстве которых получены гетерозисные и трансгрессивные гибриды, на 160-230\% превышающие по массе корнеплодов родительские сорта. На их основе созданы высокопродуктивные скороспелые линии редиса для светокультуры с урожайностью 4,5-5 кг/м² за 23-25 суток от посева. Показана перспективность работы с гибридным потомством в комбинации скрещивания редис $\times$ дайкон. Получены гетерозисные гибриды $F_{1}$ с массой корнеплода 100-150 г (товарная уро-

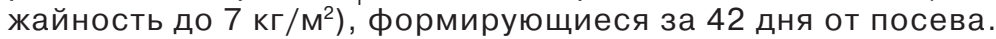

Ключевые слова: новые селекционные технологии, регулируемая агроэкосистема, биоразнообразие Raphanus sativus L., редис, дайкон, интенсивная светокультура, гетерозис, трансгрессия.
риоритетное направление современного растениеводства - создание новых сортов и гибридов различных культур, максимально реализующих потенциал продуктивности в конкретных условиях выращивания при применении современных агротехнологий. Получение нового сорта или гибрида даже при использовании новейших достижений молекулярной генетики остается весьма длительным и трудоемким процессом. В Агрофизическом НИИ предложен и апробирован на ряде культур новый подход к селекции, позволяющий значительно ускорить селекционный процесс и уменьшить объем изучаемого материала. Создана методология ускоренной селекции, базирующаяся на изучении взаимодействия «генотип - среда» в регулируемой агроэкосистеме (РАЭС), которая представляет собой физическую модель естественной агроэкосистемы в техногенной среде. В РАЭС действие основных физических факторов среды строго контролируется и может изменяться в зависимости от задач исследователя. Теоретической основой методологии служат представления об эколого-генетической организации количественных признаков, а также знания о принципах получения трансгрессий, обуславливающих прогнозируемый уровень превосходства гибридов над родителями $[1,2]$. Применение предложенной методологии значительно сокращает среднюю продолжительность селекционных схем, основанных на классических методах гибридизации и отбора растений, которая в традиционном варианте составляет для однолетних культур около 10, а для двулетних - до 20 лет [3]. Основная цель исследований - усовершенс- 
твование разработанной нами методологии ускоренной селекции при создании новых высокопродуктивных форм Raphanus sativus L., адаптированных к конкретным условиям выращивания. Одним из направлений работы было создание высокопродуктивных устойчивых форм дайкона для выращивания в открытом грунте Ленинградской области при весеннем посеве, другим - создание новых форм редиса для интенсивной светокультуры.

Условия, материалы и методы исследований. В условиях регулируемой агроэкосистемы ФГБНУ АФИ изучено более 60 образцов редиса и редьки разных эколого-географических групп и происхождения. При селекции дайкона (в 20002019 годах) изучали реакцию 35 сортов восточных редек (дайкон и лоба) на действие длинного дня (18-часовой фотопериод) и низких положительных температур в отдельности. Корнеобитаемой средой служила торфо-керамзитная смесь (3 л/ раст.), ежедневно увлажняемая раствором 1 н Кнопа. Растения выращивали под лампами ДНаТ-400 при облучении 70-80 Вт/м² ФАР. При изучении влияния длины дня образцы выращивали из не яровизированных семян при 18-часовом фотопериоде. Температуру воздуха в помещении поддерживали $22 \pm 4{ }^{\circ} \mathrm{C}$ днем и $18 \pm 2{ }^{\circ} \mathrm{C}$ ночью. При исследовании чувствительности сортов к низким положительным температурам проклюнувшиеся семена выдерживали в чашках Петри в течение 14 суток при температуре $2-4{ }^{\circ} \mathrm{C}$. Дальнейшее выращивание из них растений проводили при 12-часовом фотопериоде во избежание индуцирующего действия длинного дня. Изучение гибридного потомства $\mathrm{F}_{2}$ проводили в открытом грунте Ленинградской области на фоне действующих стрессоров при посадке в первой декаде мая.

При селекции новых форм редиса (в 2015-2019 годах) в светокультуре исследовали более 30 образцов редиса различного происхождения. Растения выращивали в оригинальной трехъярусной вегетационной светоустановке под лампами ДНа3-400 при коротком дне (12-часовой фотопериод) и облученности $50 \pm 10$ Вт/м² ФАР. Температуру поддерживали на уровне $22 \pm 4{ }^{\circ} \mathrm{C}$ днем и $18 \pm 2{ }^{\circ} \mathrm{C}$ ночью. Сухие семена высаживали в субстрат с толщиной корнеобитаемого слоя 3-4 см (верховой торф с минеральными добавками). Полив проводили ежедневно водой, чередуя с подкормкой 0,5 н раствором Кнопа (три раза в неделю). Схема посева - 5×10 см для редиса, $10 \times 10$ см - для дайкона и гибридов редис $\times$ дайкон. Размер оцениваемой выборки для каждого сорта (гибрида $F_{1}$ ) - 20-40 растений, для гибридов $\mathrm{F}_{2}-150-250$ растений, для гибридов третьего и последующих поколений - 50-100 растений. Уборку растений редиса проводили на 23-31 сутки от посева у родительских сортов и на 21-25 сутки у гибридов. Уборку сортов и гибридов дайкона и редиса проводили выборочно в три срока: на 27-е, 35-е и 42-е сутки от посева. При уборке учитывали основные биометрические показатели растения, а также процент товарных корнеплодов, степень опушенности листьев, устойчивость к стеблеванию.

Для ускорения цветения и созревания семян отобранные корнеплоды родительских сортов редиса, дайкона, лобы и гибридов первого и последующих поколений яровизировали при температуре $2-4{ }^{\circ} \mathrm{C}$ в течение 15-20 суток, при этом дальнейшее выращивание растений проводили при 16-часовом фотопериоде.

Статистическую обработку данных проводили с использованием программного обеспечения Microsoft Excel 2010.

При селекции дайкона и редиса использовали методологию ускоренной селекции [4], основные этапы которой представлены ниже:

- изучение биоразнообразия селектируемой культуры в РАЭС с целью выявления источников селектируемых признаков и их компонентов, а также степени их проявления в конкретных условиях выращивания;

- целенаправленный подбор родительских пар по принципу благоприятного взаимодополнения родителей по независимо наследуемым компонентам сложных количественных признаков (продуктивности, устойчивости к физическим стрессорам и др.);

- выращивание маточных растений для получения семян при режимах, ускоряющих генеративное развитие;

- изучение гибридов 2-4 поколений в условиях, типичных для региона селекции (открытый грунт), или в других условиях планируемого выращивания (защищенный грунт, светокультура), и выявление форм с комплексом селекционноценных признаков, превышающих родительские;
- получение из выделенных гибридных форм стабильных линий путем инбридинга и стабилизирующего отбора.

Результаты и обсуждение. Наш интерес к селекции дайкона (японская редька) связан с тем, что эта культура характеризуется интенсивным ростом, отличными вкусовыми качествами и высокой продуктивностью, что выделяет ее среди других видов редьки. В условиях муссонного климата на вулканических почвах в Японии некоторые образцы дайкона сортотипа Сакураджима образуют корнеплоды массой более 40 кг. Такие потенциальные возможности дайкона в условиях Ленинградской области не реализуются. Основное препятствие для этого - высокая чувствительность большинства имеющихся сортов к действию длинного дня и низких положительных температур в весенне-летний период, что вызывает торможение роста корнеплодов и быстрый переход растений к цветению. Разработанная нами стратегия интродукции дайкона в Северо-Западный регион России, базирующаяся на использовании методологии ускоренной селекции, предусматривала целенаправленное создание генотипов с комплексной устойчивостью к действию типичных стрессоров, вызывающих преждевременное цветение [5].

При изучении в РАЭС влияния длинного дня (18-часовой фотопериод) на рост и развитие восточных редек выявлен ряд образцов, поздно переходящих к цветению и образующих товарные корнеплоды: лоба Лу-ба-фын, Красная мелкая; дайкон - Akitsumari, Миясигэ, Terao-2ninengo, Kameido, Kawajiri, All season cross, Mino early. Влияние низких температур на эти же образцы было более сильным, значительно ускоряя переход растений к цветению и существенно тормозя рост корнеплодов у всех сортов. Наиболее устойчивыми к действию этого стрессора оказались сорта: лоба - Лу-ба-фын, Красная мелкая; дайкон - Himani, Миясигэ, Terao-2-ninengo, Kameido, Kawajiri, All season cross.

На основании проведенных сортоиспытаний подобран ряд комбинаций родительских пар для целенаправленного получения гибридных форм с комплексной устойчивостью к яровизирующим факторам. Выбор сортов диктовался не только взаимным дополнением генотипов родителей по признакам устойчивости к различным стрессорам, но и взаи- 


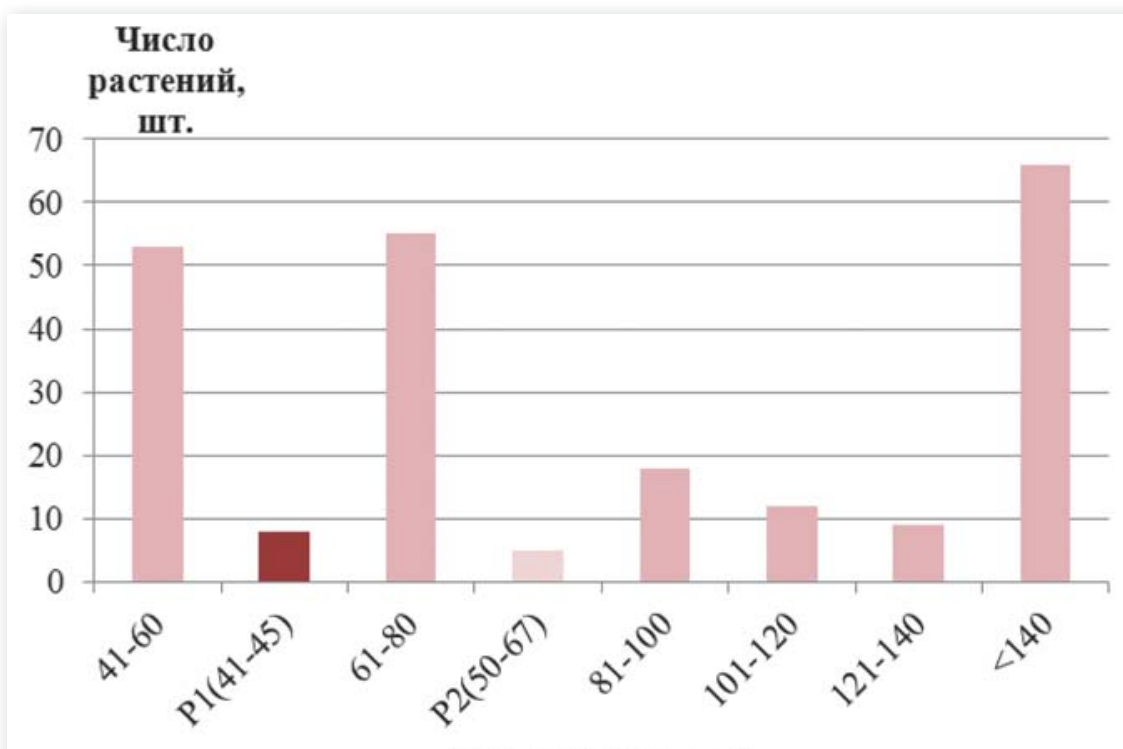

срок цветения, сvт.

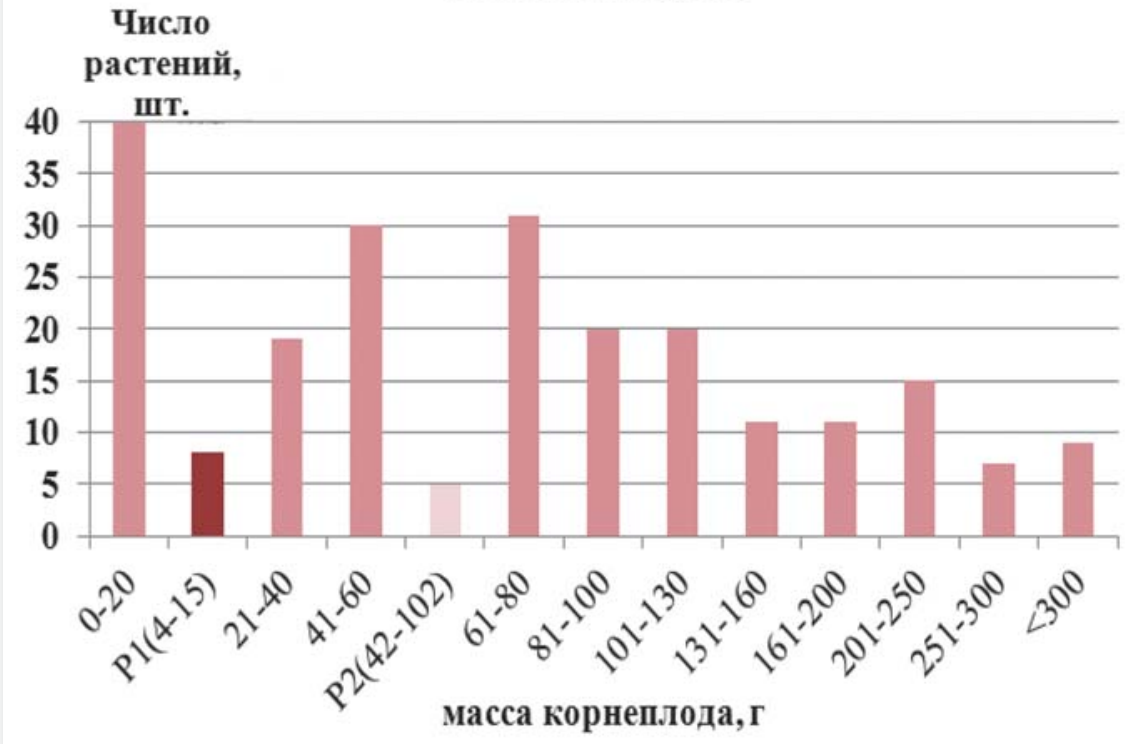

Рис. 1. Расщепление $F_{2}$ в комбинации скрещивания дайкон Акицумари $(P 1) \times$ лоба Красная мелкая (P2) по сроку цветения и массе корнеплода (открытый грунт, Ленинградская область)

модополнением по блокам генов, детерминирующих значительный диаметр корнеплода и его длину на фоне действующих стрессоров. При сравнении гибридного потомства разных комбинаций скрещивания выделена наиболее перспективная комбинация - дайкон Акицумари × лоба Красная мелкая, с которой в дальнейшем проводилась основная селекционная работа. Использование в РАЭС режимов выращивания, стимулирующих генеративное развитие (яровизация семян, корнеплодов, длинный день), позволило в минимально короткие сроки (за 1 год) получить полноценные гибридные семена $F_{1}$ и $\mathrm{F}_{2}$. Расщепление гибридов $\mathrm{F}_{2}$ изуча- ли в открытом грунте Ленинградской области (рис. 1). Основное количество гибридных растений зацвело в сроки, близкие к средним срокам перехода к цветению у родительских форм. Однако в гибридной популяции присутствовали генотипы, которые зацветали позже родительских, причем значительная часть из них не переходила к цветению до уборки опыта (140 суток). Среди устойчивых генотипов для получения семян отбирали растения с наиболее крупными, товарными, сходными по форме и окраске корнеплодами. Четко вычленить трансгрессивные (гомозиготные) генотипы в $F_{2}$ не представлялось возможным из-за значительного числа генов, детерминирующих селектируемые признаки. Исследование популяций $\mathrm{F}_{3}-\mathrm{F}_{6}$ в подобранных вариантах скрещивания показало значительное расщепление гибридов как по срокам цветения, так и по форме, цвету и массе корнеплода. Однако, уже к пятому-шестому поколению разброс по селектируемым признакам, благодаря стабилизирующему отбору и инбридингу, значительно уменьшился, и в дальнейшем были получены трансгрессивные линии дайкона, не зацветающие до конца сентября при весенней посадке с массой корнеплода 1,52 кг, превышающие лучшие родительские экземпляры по массе корнеплодов в 4-6 раз. Наиболее продуктивная линия доведена до уровня сорта и зарегистрирована под названием дайкон Петербургский [6]. Его отличительная особенность, помимо толерантности к действующим в Ленинградской области яровизирующим факторам,- компактная розетка и устойчивость к загущенным посевам, что позволяет использовать плотную посадку (10-15 см между растениями) и получать раннюю овощную продукцию (корнеплоды массой 100-150 г) уже в июле при разреживании посева. При реализации разработанной стратегии также получены трансгрессивные высокоустойчивые к стеблеванию линии дайкона и в других комбинациях скрещивания (М63, М52, Н27), с которыми ведется селекционная работа.

При создании высокопродуктивных форм редиса, адаптированных для выращивания в интенсивной светокультуре, также была использована методология ускоренной селекции. Потребность в создании оригинальных сортов редиса, реализующих свой потенциал при искусственном освещении, существует, особенно с учетом важности круглогодичного обеспечения населения северных регионов России свежей овощной продукцией. Основная задача этой работы - совмещение в одном генотипе генов, детерминирующих признаки максимальной длины и диаметра корнеплода, реализующихся в соответствующих условиях (короткий день, искусственный свет, повышенная температура). Кроме того, необходимыми требованиями к селектируемым образцам редиса было отсутствие у них стеблевания, высокая товарность корнеплодов, желательное наличие компактной розетки и неопушенного 


\section{Macca}

корнеплода, г

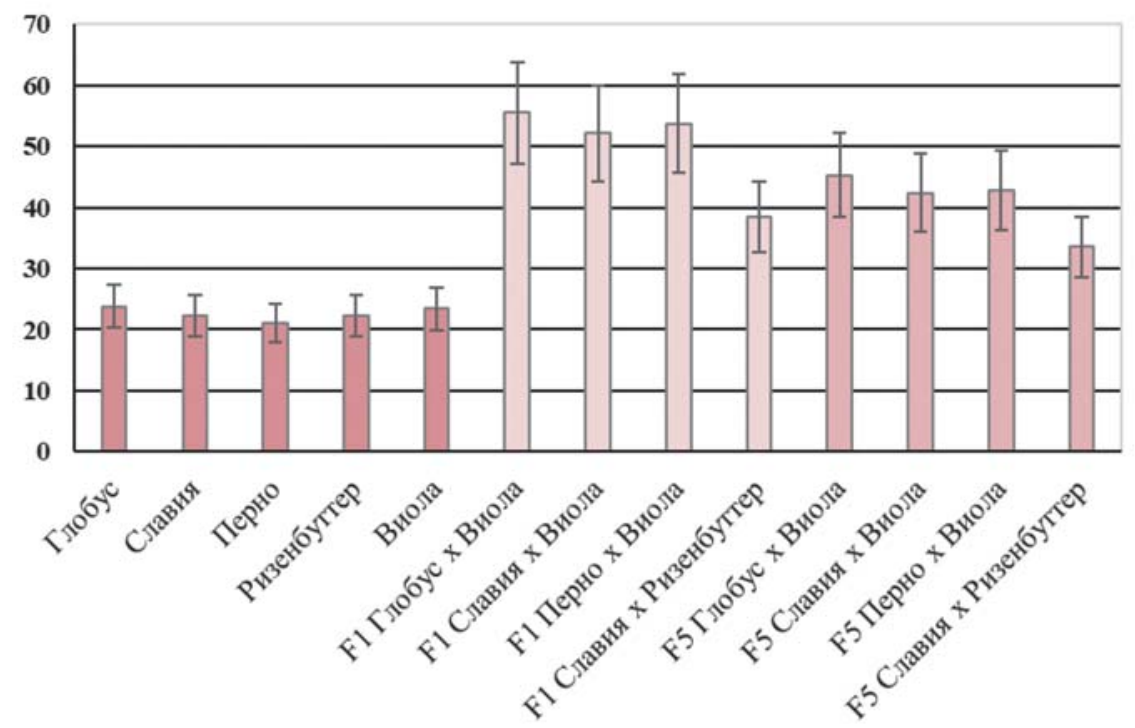

Рис. 2. Средняя масса корнеплодов родительских сортов и гибридов первого и пятого поколений в различных комбинациях скрещивания при выращивании редиса в интенсивной светокультуре (возраст растений 25 суток)

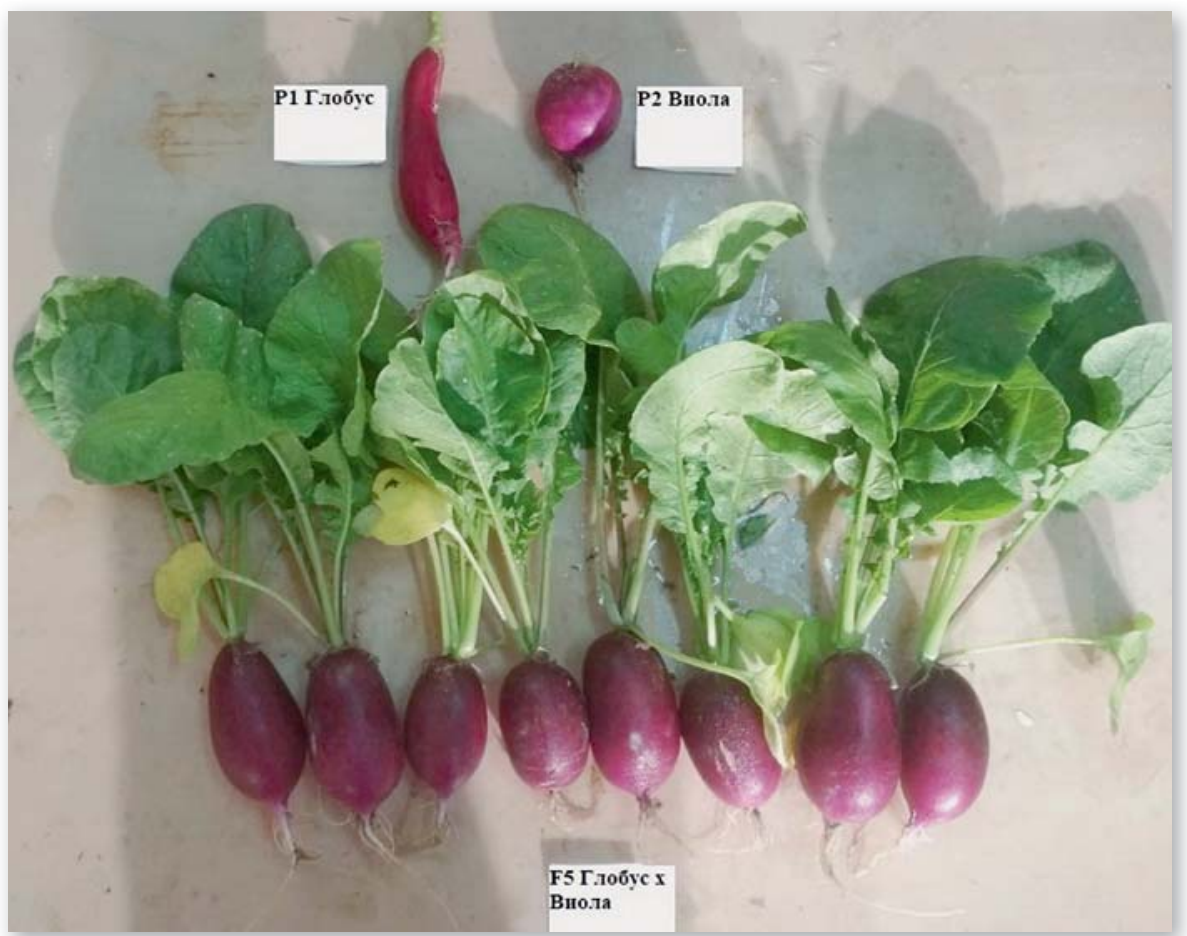

Рис. 3. Внешний вид родительских сортов и гибридов пятого поколения в комбинации скрещивания Глобус × Виола (25 суток, светокультура)

листа. Более подробно суть разработанной стратегии и основные этапы алгоритма селекции изложены авторами ранее [7]. При проведении работы в 2015-2018 годах изучено более 30 образцов редиса, каждый из которых описан по морфологическим признакам, длительности веге- тационного периода и продуктивности в светокультуре. Результаты сортоиспытаний и обоснование подбора родительских пар для получения новых форм редиса для светокультуры ранее также были описаны авторами [8]. Во всех подобранных вариантах скрещивания у гибридов перво- го поколения наблюдали эффект гетерозиса по массе корнеплода, который составил от 20 до 230\%. В лучших комбинациях скрещивания в $F_{2}$ и последующих поколениях отбирали товарные корнеплоды с максимальной массой, имеющие короткоцилиндрическую или эллиптическую форму, промежуточную между родительскими сортами. В их потомстве с помощью инбридинга и стабилизирующего отбора в 5-6 поколениях получены высокопродуктивные стабильные линии редиса, урожай товарных корнеплодов которых состав-

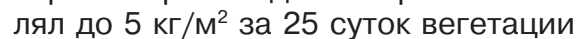
(рис. 2, 3). Продуктивность полученных в ряде комбинаций скрещиваний новых линий значительно превышала данный показатель ранее исследованных в светокультуре сортов редиса. Способ получения и стабильность полученных линий доказывают тот факт, что положительный эффект достигнут не за счет гетерозиготности, а за счет взаимодополняющего сочетания генов родителей по компонентам признака масса корнеплода при целенаправленном получении трансгрессий.

В наших исследованиях также показана перспективность работы с гибридами в комбинации скрещивания редис $\times$ дайкон. Гибридизация форм с коротким (редис) и длинным периодом вегетации (дайкон) позволяет рассчитывать на получение во втором поколении трансгрессивных генотипов со значительными различиями по темпам роста и продолжительности вегетационного периода. В качестве родительских сортов использовали сорта редиса Виола и Октава, скрещивая их с дайконом сорта Петербургский. У гибридов $\mathrm{F}_{1}$ в условиях светокультуры в этих комбинациях скрещивания наблюдали значительный гетерозис по размерам и массе корнеплода (рис. 4, 5). Особенно сильно он проявился при более поздних сроках уборки (42 сутки), когда рост родительских сортов редиса уже затормозился, а корнеплод у дайкона еще не сформировался. Отдельные экземпляры гибридов достигали по массе корнеплода 150170 г при расстоянии между растениями $10 \times 15$ см. В ближайшей перспективе - получение наследственно закрепленных линий дайкона, способных в условиях светокультуры давать

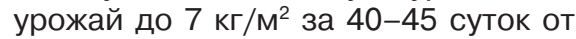
посева, а также получение высокопродуктивных гибридов редиса и дайкона для открытого грунта. 


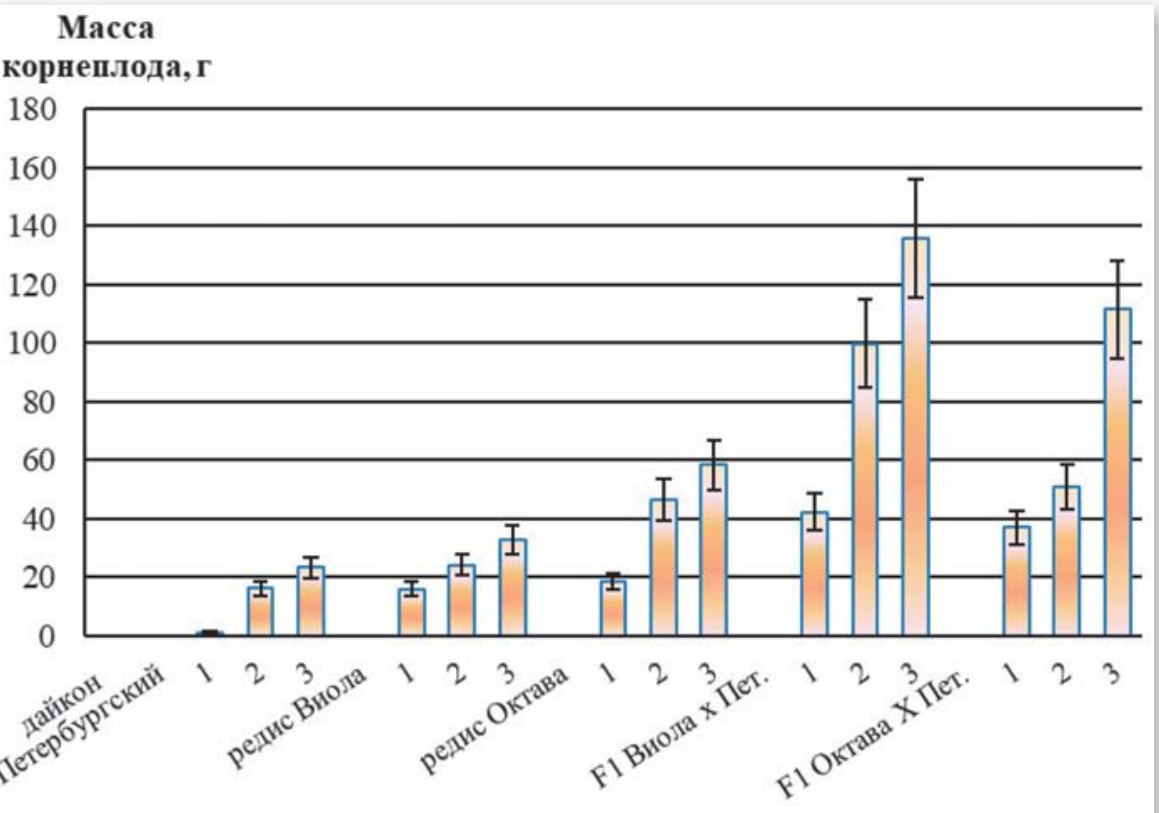

Рис. 4. Масса корнеплода родительских сортов и гибридов $F_{1}$ в комбинации скрещивания редис Октава × дайкон Петербургский, редис Виола $\times$ дайкон Петербургский (светокультура). Сроки уборки: 1-27 суток, 2-35 суток, 3-42 суток.

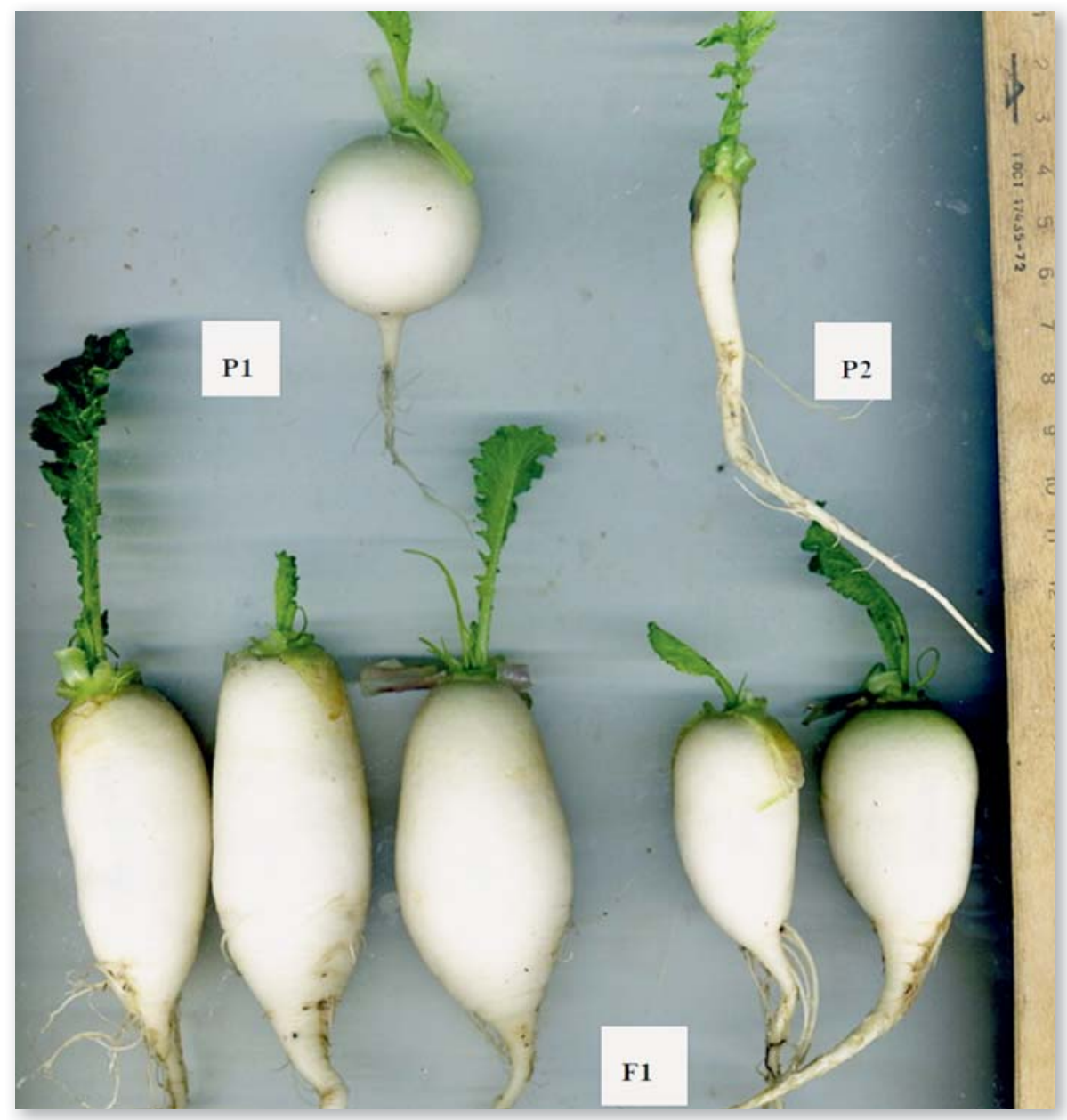

Рис. 5. Внешний вид родителей и гибридов $F_{1}$ в комбинации скрещивания редис Октава (P1) × дайкон Петербургский (P2) (возраст растений 42 дня, светокультура)
Выводы. Изучено внутривидовое разнообразие восточных редек и редиса при выращивании их в интенсивной светокультуре. Подтверждена эффективность использования разработанной оригинальной методологии прогнозируемого получения трансгрессий растений с комплексом хозяйственно ценных признаков при селекции новых форм дайкона и редиса. Идентифицированы образцы восточных редек, не переходящие к цветению в условиях длинного дня, и образцы, наиболее устойчивые к низкотемпературному стрессу. Выделены продуктивные скороспелые сорта редиса и сорта - источники генов хозяйственно ценных признаков, реализуемых в условиях искусственного освещения. Создан высокопродуктивный устойчивый к действию длинного дня и низких температур сорт дайкона Петербургский, адаптированный для выращивания в Северо-Западном регионе России при весенней посадке в открытый грунт. Урожай товарных корнеплодов дайкона Петербургский при уборке в конце сентября достигал 12 кг/м². Получены высокопродуктивные стабильные линии редиса для использования в интенсивной светокультуре с урожайностью товарных корнеп-

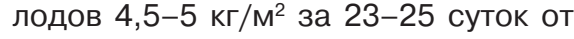
посева. Показана перспективность селекционной работы с гибридами Raphanus sativus L. в комбинациях скрещивания редис х дайкон для использования в светокультуре. Получены гетерозисные гибриды $\mathrm{F}_{1}$ с массой корнеплода 100-150 г (уро-

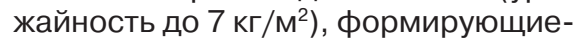
ся за 42 дня от посева.

\section{Библиографический список}

1.Драгавцев В.А., Литун П.П., Шкель Н.М., Нечипоренко Н.Н. Модель эколого-генетического контроля количественных признаков растений // Доклады AH CCP. 1984. T. 274. № 3. C. 720-723.

2.Кочетов А.А., Макарова Г.А., Мирская Г.В., Синявина Н.Г. Агрофизический подход к созданию новых форм культурных растений // Агрофизика. 2012. №1. С. $40-44$.

3.Журавлева Е.В. Селекция и семеноводство - комплексный подход, современное состояние и перспективы // Достижения науки и техники АПК. 2015. Т. 29. № 12. C. 5-7.

4.Методология прогнозирования трансгрессий по хозяйственно-ценным признакам растений / Г.А. Макарова, Г.В. Мирская, А.А. Кочетов, Н.Г. Синявина, В.А. Драгавцев. СПб., 2009. 48 с.

5.Кочетов А.А. Генотипическая адаптация восточноазиатских подвидов Raphanus sativus при интродукции в Северо-Западный регион России [Редька: дайкон и лоба] // Сельскохозяйственная биология. Сер. Биология растений. 2004. № 1. С. 83-91.

6.Государственный реестр селекционных достижений, допущенных к использованию. в 2018 году / Официальный сайт ФБНУ «Государственная комиссия Российской Федерации по испытанию и охране селекционных достижений» (ФГБУ «Госсорткомиссия») 
[Электронный ресурс]. URL: http://reestr.gossort. comhttps://reestr.gossort.com/. Дата обращения: 01.07.2019.

7.Кочетов А.А., Синявина Н.Г. Стратегия создания высокопродуктивных форм редиса, адаптированных для выращивания в светокультуре // Российская сельскохозяйственная наука. 2019. № 1. С. 26-30.

8.Синявина Н.Г. и др. Изучение биоразнообразия редиса в условиях интенсивной светокультуры и выявле ние доноров хозяйственно ценных признаков для селекции // Овощи России. 2018. № 3. С. 56-59.

\section{Об авторах}

Кочетов Алексей Александрович, канд. биол. наук, зав. лабораторией экологической генетики и селекции растений.

E-mail: kochetoval@yandex.ru

Синявина Надежда Георгиевна, канд. биол. наук, С.н.с. лаборатории экологической генетики и селекции растений. E-mail: sinad@inbox.ru ФГБНУ Агрофизический научно-исследовательский институт

Creation of new forms of Raphanus sativus $L$. with the predicted complex of economically valuable traits using the methodology of accelerated plant breeding

A.A. Kochetov, $P h D$, head of laboratory of ecological genetics and plant breeding. E-mail: kochetoval@yandex.ru

N.G. Sinyavina, PhD, senior research fellow of laboratory of ecological genetics and plant breeding. E-mail: sinad@inbox.ru FSBSI Agrophysical Research Institute
Summary. New highly productive forms of Raphanus sativus $L$. were obtained at the Agrophysical Research Institute (FSBSI $A R I)$ agrophysical Research Institute), using the original methodology of accelerated breeding. They are intended for cultivation in the open ground of the Leningrad Region (daikon) and under conditions of intensive light culture (small radish lines and $F_{1}$ hybrids of small radish and daikon). The aim of the research is to improve the methodology of accelerated selection developed by the authors for the creation of new highly productive forms of Raphanus sativus $L$. adapted to specific growing conditions. At first stage, the intraspecific diversity of root crops of the species Raphanus sativus $L$. (more than 60 cultivars of different groups and origin) was studied in intense light culture. Plants were grown under DNAT-400 and DRIKZ-400 lamps with irradiation intensity of $70-80 \mathrm{~W} / \mathrm{m}^{2}$ of PAR. Root medium was the peat with mineral additives, moisturize daily with a Knop solution by alternating with water. The reactions of different varieties of the East Asian radishes (35 cultivars) on long day conditions (18-hour photoperiod) and low spring temperatures were evaluated. The most resistant to these stressors cultivars were identified, and hybridization of them produced transgressive forms of daikon with complex resistance. The revealing of these forms and the subsequent stabilizing selection were performed in the open ground in the Leningrad region at sowing in the first decade of may. As a result of the research, a highly productive variety of daikon Peterburgskyi, adapted to spring sowing in the open ground of the Leningrad region, was obtained. When breeding new forms of radish for light culture, the collection of cultivars of different origin was studied and varieties were identified with a yield of commercial root crops up to $3 \mathrm{~kg} / \mathrm{m}^{2}$ for 25 days of vegetation, as well as varieties that are sources of economically valuable traits implemented in conditions of intensive light culture (the maximum length/diameter of the root crop, early maturity, resistance to bolting, compact rosette, glabrous leaf type and etc). Combinations of crosses were selected, in the progeny of which heterotic and transgressive hybrids are obtained, that are 160-230\% higher than the parent varieties by weight of root crops. On their basis, highly productive early ripening lines of radish for light culture were created with a yield of $4.5-5 \mathrm{~kg} / \mathrm{m}^{2}$ for 23-25 days from sowing. Moreover, the prospectivity of selection work with hybrid offspring in a crossbreeding combination of small radish and daikon in light culture is shown. Heterotic $F_{1}$ hybrids with a root mass of 100-150 g (yield up to $7 \mathrm{~kg} / \mathrm{m}^{2}$ ) formed 42 days after sowing, were obtained.

Keywords: new breeding technologies, regulated agroecosystem, biodiversity of Raphanus sativus L., small radish, daikon, intensive light culture, heterosis, transgression.

\section{Донские фермеры объединяются в сельхозкооперативы}

В конце сентября в Ростове-на-Дону при поддержке областного правительства состоялся VII форум «Донской фермер» и конференция сельских кооператоров.

На одной площадке встретились фермеры, владельцы личных подсобных хозяйств, кооператоры, представители исполнительной и законодательной власти и общественных объединений и институтов развития малого и среднего предпринимательства.

Мероприятие объединило в себе ряд дискуссионных площадок, среди которых диалог бизнеса с властью с участием министра сельского хозяйства и продовольствия Дона Константина Рачаловского, круглый стол центра компетенций в сфере с.-х. кооперации Ростовской области и др.

Итоговым мероприятием стало пленарное заседание областной конференции сельских кооперативов и фермеров. Выступая на ней, первый заместитель губернатора Ростовской области Виктор Гончаров отметил, что в Ростовской области большое внимание уделяется развитию малого агробизнеса - фермерским хозяйству и сельским кооперативам. Для стимулирования их развития предоставляется более 30 видов государственных поддержек.

Так, с 2010 по 2018 год объем финансирования малых форм хозяйствования увеличился более чем в 4,5 раза: с 300 млн р. до 1,4 млрд р. В последние два года система льготного кредитования помогает решить ряд вопросов со стоимостью кредитных средств, так как малые формы хозяйствования находятся в привилегированном положении. Кроме того, уже восемь лет (с 2012 года) в Ростовской области реализуются грантовые программы для создания новых, в том числе овощеводческих, фермерских хозяйств. Участниками программ, получившими средства господдержки, стали почти 700 хозяйств.

Также во время конференции обсудили новые возможности для малых форм хозяйствования, открывающиеся в рамках реализации нацпроектов. Так, согласно региональному проекту «Создание системы поддержки фермеров и развитие сельской кооперации» до 2024 года на территории Ростовской области в субъекты малого и среднего предпринимательства АПК должно быть вовлечено 1200 человек. На выполнение показателей будет направлено порядка 600 млн. р. Средства пойдут на предоставление грантов «Агростартап» новым фермерам и выплату субсидий сельхозкооперативам.

Источник: www.kvedomosti.ru 